\title{
Soleus muscle H-reflex monitoring in endoscopic surgery under general anesthesia percutaneous interlaminar approach
}

\author{
HUIXUE WANG ${ }^{1}$, YINGJI GAO ${ }^{1}$, LIXIN JI ${ }^{1}$ and WANSHAN BAI ${ }^{2}$ \\ ${ }^{1}$ Department of Spinal Surgery, People's Hospital of Linyi, Linyi, Shandong 276003; ${ }^{2}$ Department of Neurosurgery, \\ Jinling Hospital, School of Medicine, Nanjing University, Nanjing, Jiangsu 210002, P.R. China
}

Received December 14, 2017; Accepted February 16, 2018

DOI: $10.3892 /$ etm.2018.5979

\begin{abstract}
The clinical value of soleus muscle H-reflex monitoring in general anesthesia percutaneous interlaminar approach was investigated. A total of 80 cases with unilateral L5-S1 disc herniation between January 2015 and October 2016 were randomly divided into control group (without soleus muscle $\mathrm{H}$-reflex monitoring, $\mathrm{n}=40$ ) and observation group (with soleus muscle H-reflex monitoring, $n=40$ ). Results showed that the operation time of the observation group was shorter than that of the control group $(\mathrm{P}<0.05)$, and the blood loss during the operation was less than that of the control group $(\mathrm{P}<0.05)$. The length of postoperative hospital stay was shorter than that of the control group $(\mathrm{P}<0.05)$. At $24 \mathrm{~h}$ after operation, the amplitude of $\mathrm{H}$-reflex in diseased side soleus muscle was significantly lower than that in healthy side $(\mathrm{P}<0.05)$. The preoperative, postoperative and $24 \mathrm{~h}$ postoperatively, the latency of H-reflex in diseased side soleus muscle was shorter than that of healthy side $(\mathrm{P}<0.05)$. The latency and amplitude of H-reflex latency in soleus muscle were significantly lower $(\mathrm{P}<0.05)$, and the height of intervertebral space in observation group was significantly higher than that in control group $(\mathrm{P}<0.05)$. The total percentage of postsurgical sensory dysfunction, dyskinesia, post-root canal stenosis, disc herniation and cerebrospinal fluid leakage was lower than that of the control group $(\mathrm{P}<0.05)$. Japanese Orthopaedic Association score of the observation group was significantly higher at 1 month, and 1 year after operation lower than the control group $(\mathrm{P}<0.05)$. Taken together, soleus muscle H-reflex monitoring can effectively reduce the damage to the nerve roots under percutaneous endoscopic intervertebral endoscopic surgery under general anesthesia, improve the accuracy of surgery, reduce the complications, shorten the operation time and reduce the surgical bleeding, which is more beneficial to patients smooth recovery.
\end{abstract}

Correspondence to: Dr Wanshan Bai, Department of Neurosurgery, Jinling Hospital, School of Medicine, Nanjing University, 305 East Zhongshan Road, Xuanwu, Nanjing, Jiangsu 210002, P.R. China

E-mail: bai788ws@163.com

Key words: H-reflex monitoring, soleus, general anesthesia, percutaneous interlaminar approach endoscopic surgery

\section{Introduction}

The surgical treatment of intervertebral disc herniation is currently the most effective intervention method for patients with lumbar intervertebral disc herniation, but there is a certain proportion of nerve root injury or even spinal cord injury (1), thereby causing great negative impacts on patients (2). At present, there are many anesthesia methods in intervertebral disc surgery, such as local anesthesia, epidural anesthesia with motor function retained and general anesthesia (3). During surgery, the operation near the nerve root will lead to nerve tingling and other severe discomfort in patients, so how to effectively alleviate the patient's discomfort and improve the surgical safety are the research emphases at present (4).

There are many qualitative methods of non-invasive electrophysiological detection of nerve root or spinal cord injury, including $\mathrm{H}$-reflex monitoring, F-wave detection and maximum $\mathrm{H}$-wave amplitude measurement (5), among which the H-reflex monitoring of soleus muscle can effectively reflect the $\mathrm{S} 1$ nerve function (6) and can be used as the most effective monitoring index of surgery of lumbar intervertebral disc (7). In this study, therefore, the application value of H-reflex monitoring of soleus muscle in the endoscopic surgery via percutaneous interlaminar approach under general anesthesia was mainly investigated.

\section{Patients and methods}

General materials. A total of 80 patients with unilateral L5-S1 intervertebral disc herniation treated in Jinling Hospital (Nanjing, China) from January 2015 to October 2016 were selected, and they were all diagnosed via clinical manifestations, signs and imaging combined with electrophysiological examination. All patients enrolled were fully informed of the enrollment and voluntarily signed the informed consents, and this study was approved by the Medical Ethics Committee of Jinling Hospital (Nanjing, China). Before enrollment, patients had significant clinical symptoms and/or signs, radiating pain in the lower limb, numbness of limb, hypokinesis and decreased muscle function on the affected side; moreover, the magnetic resonance examination of lumbar vertebra showed that the patients suffered from lumbar intervertebral disc herniation complicated with nerve root compression on the affected side. Patients whose H-reflex of soleus muscle was 
A

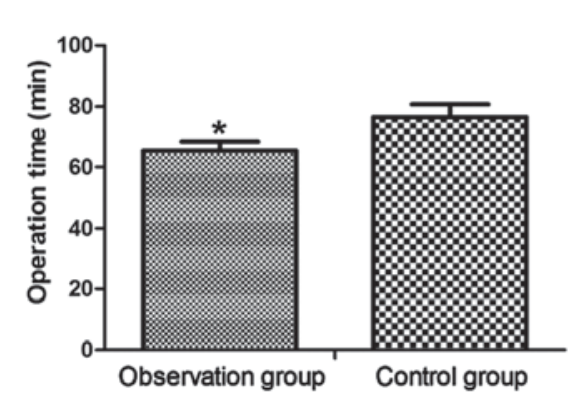

B

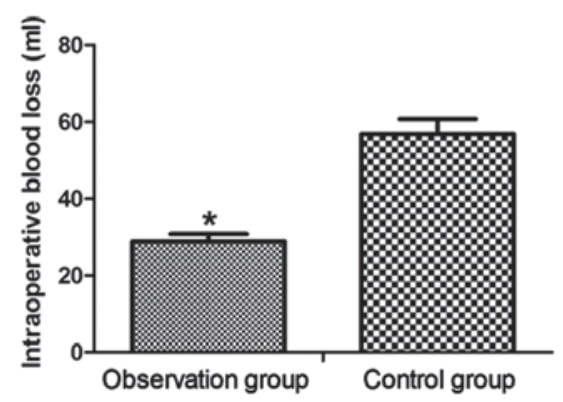

C

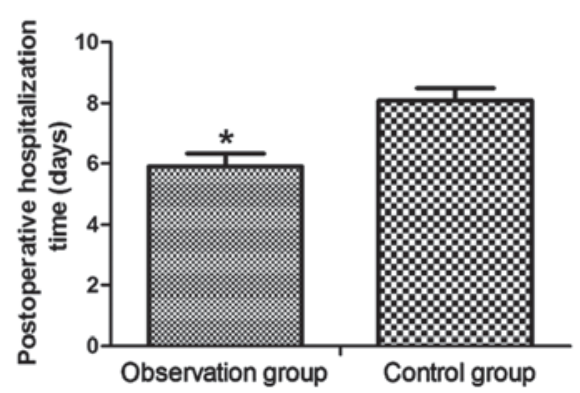

Figure 1. Comparisons of operation time, intraoperative blood loss and postoperative hospitalization time between two groups. (A) The operation time in observation group is shorter than that in control group ( $\left.{ }^{*} \mathrm{P}<0.05\right)$; $(\mathrm{B})$ the intraoperative blood loss amount in observation group is less than that in control group $\left({ }^{*} \mathrm{P}<0.05\right)$; and $(\mathrm{C})$ the postoperative hospitalization time in observation group is shorter than that in control group $\left({ }^{*} \mathrm{P}<0.05\right)$.

not induced before enrollment, or those complicated with motor neuron disease, syringomyelia, benign or malignant spinal tumors, spinal deformity, fracture of lower limb, muscle atrophy of lower limb, multiple nerve disease, malnutrition, acute trauma, significant systemic inflammation, local infection, central nervous system disease, or who used to receive spinal surgery-related treatment were eliminated. Patients were divided into two groups with 40 cases in each group using the random number method. In observation group, there were 27 males and 13 females aged 25-60 years with an average of $43.5 \pm 2.1$ years; the course of disease was 3 months to 6 years with an average of $1.5 \pm 0.2$ years; in terms of occurrence site, there were 17 cases on the left, and 23 cases on the right. In control group, there were 26 males and 14 females aged 25-60 years with an average of 43.6 \pm 2.1 years; the course of disease was 3 months to 6 years with an average of $1.6 \pm 0.2$ years; in terms of occurrence site, there were 16 cases on the left, and 24 cases on the right. There were no statistically significant differences in comparisons of sex, age, course of disease, or occurrence site, between the two groups $(\mathrm{P}>0.05)$.

Methods. Under general anesthesia, all patients underwent endoscopic intervertebral disc radiofrequency ablation via percutaneous translaminar approach using tracheal intubation. The operation in control group was mainly performed based on the clinical experience of surgeon, intraoperative identification should be strengthened, and surgical complications should be avoided. In observation group, H-reflex monitoring of soleus muscle was performed following the specific steps below: Nikon Kohden MEB 9400 (Nikon Corporation, Tokyo, Japan) electromyogram tester was used to detect the H-reflex of soleus muscle, in which the surface stimulating electrode was placed in the popliteal fossa and at $2 \mathrm{~cm}$ below medial and lateral heads of gastrocnemius muscle, and the reference control electrode was placed at $3 \mathrm{~cm}$ above the Achilles's tendon line. The stimulus wave width was adjusted into $1.0 \mathrm{~ms}$, the filtering frequency was $10 \mathrm{~Hz}-10 \mathrm{kHz}$, and the initial current was set to $0.5 \mathrm{~mA}$; during operation, the current stimulus intensity was gradually increased until the maximum-amplitude H-reflex appeared, with the single stimulus interval of $10 \mathrm{sec}$ and the body surface temperature controlled at $34^{\circ} \mathrm{C}$ and above. Once H-reflex amplitude occurred or the latency time was decreased by more than $85 \%$, surgical stimulus was withdrawn immediately, and the surgical operation was adjusted.
Observation indexes. The operation time, intraoperative blood loss and postoperative hospitalization time were compared between two groups. The amplitude and latency time of H-reflex of soleus muscle before and after operation in observation group were compared. Besides, the changes in relevant parameters to H-reflex of soleus muscle on the affected side in different operations during surgery were recorded, the changes in intervertebral space height before and after operation were compared between two groups, and related complications and changes in Japanese Orthopaedic Association (JOA) score were recorded.

The clinical efficacy on spinal cord function was scored using JOA scoring method, including four aspects (subjective feeling, clinical symptoms, daily activities and bladder function). The total score is $0-29$ points; the lower the score is, the more obvious the functional disorder will be.

Statistical analysis. SPSS 13.0 (SPSS, Inc., Chicago, IL, USA) was used for statistical analysis. Measurement data are presented as mean \pm standard deviation (mean \pm SD), t-test was used for the comparison of means between two groups, repeated measurement analysis of variance was used for the intragroup comparison of means at different observation time-points, and Chi-square test was used for the intergroup comparison of rates. $\mathrm{P}<0.05$ was considered to indicate a statistically significant difference.

\section{Results}

Comparison of operation time, intraoperative blood loss and postoperative hospitalization time in the two groups. The operation time in observation group $(65.5 \pm 2.1 \mathrm{~min})$ was shorter than that in control group $(76.5 \pm 3.2 \mathrm{~min})(\mathrm{t}=18.176, \mathrm{P}<0.05)$; the intraoperative blood loss amount in observation group $(28.9 \pm 1.7 \mathrm{ml})$ was less than that in control group $(56.8 \pm 5.6 \mathrm{ml})$ $(\mathrm{t}=30.151, \mathrm{P}<0.05)$; the postoperative hospitalization time in observation group (5.9 \pm 1.1 days) was shorter than that in control group (8.1 \pm 1.5 days) $(\mathrm{t}=7.378, \mathrm{P}<0.05$; Fig. 1$)$.

Comparison of changes in $H$-reflex amplitude of soleus muscle before and after operation. Before operation, immediately after operation and at $24 \mathrm{~h}$ after operation, the H-reflex amplitude of soleus muscle on the affected side was significantly lower than that on the unaffected side $(\mathrm{P}<0.05$; Table I). 
Table I. Comparison of changes in H-reflex amplitude of soleus muscle before and after operation $(\mathrm{mV}$, mean $\pm \mathrm{SD})$.

\begin{tabular}{lccc}
\hline Soleus muscle & $\begin{array}{c}\text { Before } \\
\text { operation }\end{array}$ & $\begin{array}{c}\text { Immediately } \\
\text { after operation }\end{array}$ & $\begin{array}{c}\text { Twenty-four } \\
\text { hours after } \\
\text { operation }\end{array}$ \\
\hline Unaffected side & $3.59 \pm 0.15$ & $3.60 \pm 0.15$ & $3.61 \pm 0.14$ \\
Affected side & $1.78 \pm 0.13$ & $1.66 \pm 0.14$ & $1.73 \pm 0.15$ \\
t-test & 57.671 & 59.799 & 57.949 \\
P-value & $>0.05$ & $>0.05$ & $>0.05$ \\
\hline
\end{tabular}

Table II. Comparisons of latency time of H-reflex of soleus muscle before and after operation $(\mathrm{ms}$, mean $\pm \mathrm{SD})$.

\begin{tabular}{lccc}
\hline Soleus muscle & $\begin{array}{c}\text { Before } \\
\text { operation }\end{array}$ & $\begin{array}{c}\text { Immediately } \\
\text { after operation }\end{array}$ & $\begin{array}{c}\text { Twenty-four } \\
\text { hours after } \\
\text { operation }\end{array}$ \\
\hline Unaffected side & $27.8 \pm 0.29$ & $25.3 \pm 0.21$ & $28.6 \pm 0.30$ \\
Affected side & $29.1 \pm 0.32$ & $29.1 \pm 0.33$ & $29.0 \pm 0.32$ \\
t-test & 19.039 & 61.442 & 5.767 \\
P-value & $>0.05$ & $>0.05$ & $>0.05$ \\
\hline
\end{tabular}

Table III. Comparisons of intervertebral space height before and after operation between two groups ( $\mathrm{mm}$, mean $\pm \mathrm{SD})$.

\begin{tabular}{lcccc}
\hline Groups & $\begin{array}{c}\text { Before } \\
\text { operation }\end{array}$ & $\begin{array}{c}\text { One year after } \\
\text { operation }\end{array}$ & $\mathrm{t}$ & P-value \\
\hline Observation & $8.15 \pm 0.15$ & $8.13 \pm 0.10$ & 0.702 & 0.485 \\
Control & $8.16 \pm 0.15$ & $7.65 \pm 0.12$ & 16.791 & $>0.05$ \\
t-test & 0.298 & 19.435 & - & - \\
P-value & 0.766 & $>0.05$ & - & - \\
\hline
\end{tabular}

Comparison of latency time of H-reflex of soleus muscle before and after operation. Before operation, immediately after operation and at $24 \mathrm{~h}$ after operation, the latency time of H-reflex of soleus muscle on the affected side was significantly shorter than that on the unaffected side $(\mathrm{P}<0.05$; Table II).

Changes in relevant parameters to H-reflex of soleus muscle on the affected side in different operations during surgery. In the nerve root exposure, nerve root stripping and nerve root displacement, the latency time of $\mathrm{H}$-reflex of soleus muscle was: $26.3 \pm 0.23,23.9 \pm 0.19$, and $25.3 \pm 0.21 \mathrm{~ms}$, respectively $(\mathrm{t}=6.328$, $\mathrm{p}=0.011<0.05)$, and the H-reflex amplitude of soleus muscle was: $1.85 \pm 0.09,1.33 \pm 0.02$, and $1.83 \pm 0.08 \mathrm{mV}$, respectively $(\mathrm{t}=5.206, \mathrm{p}=0.021<0.05)$. Among them, nerve root stripping had the greatest effects on the latency time and amplitude of H-reflex of soleus muscle (Fig. 2).

Comparison of intervertebral space height before and after operation between two groups. There was no statistically significant difference in the comparison of intervertebral
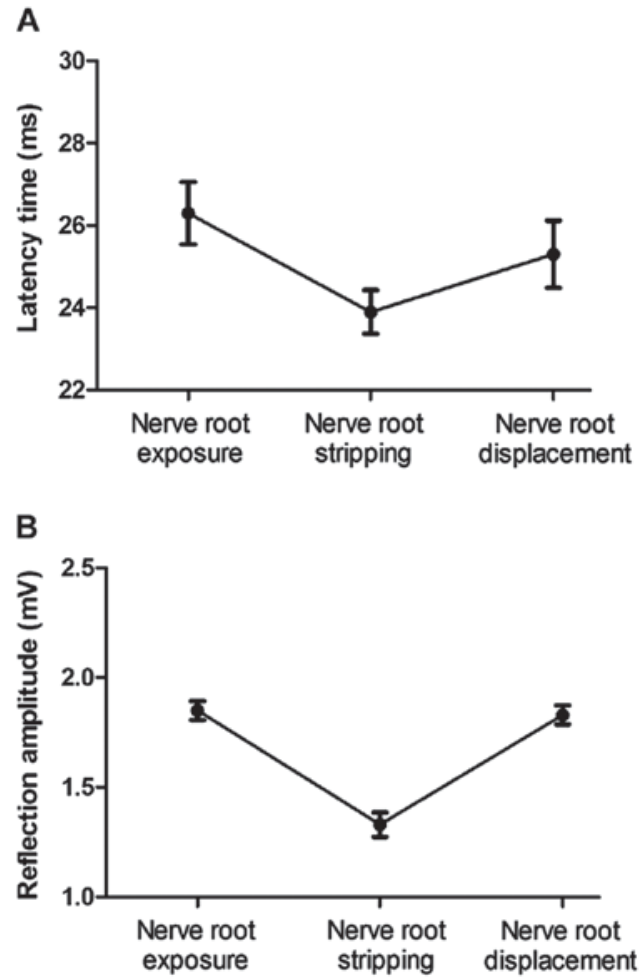

Figure 2. Changes in relevant parameters to H-reflex of soleus muscle on the affected side in different operations during surgery. (A) The latency time; and (B) amplitude of H-reflex of soleus muscle are significantly decreased in nerve root stripping $(\mathrm{P}<0.05)$

space height between two groups before operation $(\mathrm{P}>0.05)$. The intervertebral space height in observation group at 1 year after operation was significantly higher than that in control group $(\mathrm{P}<0.05$; Table III).

Comparisons of complications between two groups. Patients were followed-up for 1 year; results showed that the total proportion of postoperative sensory disturbance, dyskinesia, postoperative nerve root canal stenosis, recurrent herniation of intervertebral disc and cerebrospinal fluid leakage in observation group $(12.5 \%)$ was significantly lower than that in control group $(50.0 \%)\left(\chi^{2}=13.091, \mathrm{P}<0.05\right)($ Table IV).

Changes in JOA scores during treatment and follow-up between two groups. Before operation, and at 1 month and 1 year after operation, the JOA scores were: $13.2 \pm 0.9,19.8 \pm 1.5$, and $23.5 \pm 1.6$ points, respectively, in observation group; and $13.3 \pm 0.9,15.5 \pm 1.3$, and $20.3 \pm 1.5$ points, respectively, in control group. There was no statistically significant difference in the comparison of JOA score between two groups before operation $(\mathrm{F}=0.497, \mathrm{p}=0.621>0.05)$; the JOA scores in observation group at 1 month and 1 year after operation were significantly lower than those in control group in the same periods $(\mathrm{F}=13.701$ and 9.228, P<0.05; Fig. 3).

\section{Discussion}

Presently, lumbar intervertebral disc herniation is a clinically common disease that causes pain in the waist back and the lower limbs, and the open posterior discectomy is often needed 
Table IV. Comparisons of related complications between two groups (n).

\begin{tabular}{|c|c|c|c|c|c|}
\hline Groups & $\begin{array}{c}\text { Sensory } \\
\text { disturbance }\end{array}$ & Dyskinesia & $\begin{array}{l}\text { Postoperative nerve } \\
\text { root canal stenosis }\end{array}$ & $\begin{array}{l}\text { Recurrent herniation } \\
\text { of intervertebral disc }\end{array}$ & $\begin{array}{c}\text { Cerebrospinal fluid } \\
\text { leakage }\end{array}$ \\
\hline Observation & 1 & 1 & 1 & 2 & 0 \\
\hline Control & 3 & 2 & 5 & 7 & 3 \\
\hline
\end{tabular}

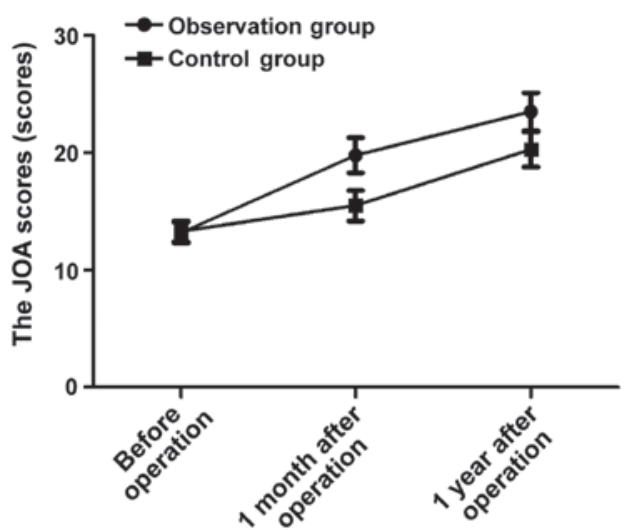

Figure 3. Changes in JOA scores during treatment and follow-up between two groups. The JOA scores in observation group at 1 month and 1 year after operation are significantly lower than those in control group in the same periods $(\mathrm{P}<0.05)$. JOA, Japanese Orthopaedic Association.

in the surgical treatment of lumbar intervertebral disc herniation (8). In recent years, with the development of endoscopic technique, percutaneous transforaminal endoscopic technique has been increasingly widely used in clinical practice, which is characterized by small trauma, quick postoperative recovery, and few complications (9). Interlaminar approach effectively simplifies the operation and improves the safety of surgical treatment, but it may cause nerve root traction (10), leading to nerve root injury in patients. If the local anesthesia or intraspinal epidural anesthesia is used, the intraoperative pain and discomfort will be produced (11). In order to improve the comfort of patients, studies have reported that it is considered to adopt general anesthesia in surgical treatment (12). Under general anesthesia, however, surgeons cannot communicate with the patient in time during operation, failing to prevent the intraoperative nerve root injury, so the promotion of this surgical approach is affected (13). H-reflex of soleus muscle can effectively reflect the function of S1 nerve root, and it was used first to monitor the nerve function in spinal surgery in the 1990 s, thereby reducing the nerve root injury and its complications (14).

In this study, all patients underwent surgical treatment under general anesthesia. H-reflex monitoring of soleus muscle was performed for patients in observation group. Compared with those in control group, the operation time in observation group was shorter, the intraoperative blood loss amount was less and the postoperative hospitalization time was shorter, suggesting that performing H-reflex monitoring of soleus muscle in endoscopic surgery via percutaneous interlaminar approach under general anesthesia can effectively shorten the operation time and hospitalization time, and reduce the intraoperative blood loss amount of patients. In addition, the comparisons of amplitude and latency time of H-reflex of soleus muscle of patients in observation group before and after operation showed that the amplitude and latency time of H-reflex of soleus muscle on the affected side before operation, immediately after operation and at $24 \mathrm{~h}$ after operation were significantly lower and shorter than those on the unaffected side, indicating that the H-reflex monitoring of soleus muscle can effectively determine the nerve function, and determine the S1 nerve function more intuitively. At the same time, the research on the operations of nerve root during surgery showed that the amplitude and latency time of H-reflex of soleus muscle in nerve root stripping were significantly reduced, suggesting that nerve root stripping during surgery has the greatest effect on the nerve conduction function of nerve root, and attention should be paid to it during surgery, reducing the damage as far as possible. Moreover, the comparison of intervertebral space height between two groups before and after operation found that the intervertebral space height in observation group at 1 year after operation was obviously larger than that in control group, indicating that performing the H-reflex monitoring of soleus muscle in endoscopic surgery via percutaneous interlaminar approach under general anesthesia can improve the surgical effect more effectively, and reduce the loss of intervertebral space height after operation. Besides, patients were followed-up for 1 year, and the research on the complications showed that the total proportion of postoperative sensory disturbance, dyskinesia, postoperative nerve root canal stenosis, recurrent herniation of intervertebral disc and cerebrospinal fluid leakage in observation group (12.5\%) was significantly lower than that in control group (50.0\%), indicating that H-reflex monitoring of soleus muscle has positive significance in reducing the surgical complications. Finally, changes in JOA scores in both groups during treatment and follow-up revealed that the JOA scores in observation group at 1 month and 1 year after operation were significantly lower than those in control group in the same periods, further suggesting that performing the H-reflex monitoring of soleus muscle in endoscopic surgery via percutaneous interlaminar approach under general anesthesia is of great significance in improving the limb function after operation.

Previous studies have confirmed (15) that the latency time and amplitude of H-reflex of soleus muscle can be used as sensitive indexes of S1 nerve root injury, the former of which can reflect the nerve conduction function and speed (16); the change in amplitude can reflect the synchronous capacity of nerve fiber conduction (17). Operations of nerve root during surgery, such as nerve root exposure, nerve root stripping and nerve root displacement, may result in localized ischemia, followed by short-term and mild nerve demyelination (18). At this time, the latency time and amplitude of H-reflex of soleus 
muscle changed more obviously. H-reflex monitoring of soleus muscle in observation group (19) can reflect the conditions of nerve root steadily and continuously, and the intraoperative nerve root injury will immediately lead to the change in relevant data, thus better guiding the surgeon to adjust the surgical operation in time and reducing complications (20).

In conclusion, H-reflex monitoring of soleus muscle can effectively reduce the nerve root injury caused by endoscopic surgery via percutaneous interlaminar approach under general anesthesia, improve the accuracy of surgery, reduce the complications, shorten the operation time, and reduce the intraoperative blood loss, thus benefiting the smooth rehabilitation of patients more.

\section{Acknowledgements}

Not applicable.

\section{Funding}

No funding was received.

\section{Availability of data and materials}

All data generated or analyzed during this study are included in this published article.

\section{Authors' contributions}

HW designed the study, YG and LJ collected and analysed the data, WB and HW wrote the manuscript. WB and HW performed the follow-up. All authors read and approved the final manuscript.

\section{Ethics approval and consent to participate}

This study was approved by the Ethics Committee of Jinling Hospital (Nanjing, China). Signed written informed consents were obtained from the patients and/or guardians.

\section{Consent for publication}

Not applicable.

\section{Competing interests}

The authors declare that they have no competing interests.

\section{References}

1. Lipman SL, Rouze NC,Palmeri ML and Nightingale KR: Evaluating the improvement in shear wave speed image quality using multidimensional directional filters in the presence of reflection artifacts. IEEE Trans Ultrason Ferroelectr Freq Control 63: 1049-1063, 2016.

2. Priyadarshini M, Machavaram VR, Sivaramakrishna A and Arulmozhivarman P: Detecting phase transitions in a $\mathrm{CaCl}<$ sub $>2</$ sub $>-\mathrm{H}<$ sub $>2</$ sub $>0$ system at low temperatures using a fiber-optic Fresnel reflection sensor.Appl Opt 56:3229-3239, 2017.

3. Wong EP, Yon L, Purcell R, Walker SL, Othman N, Saaban S and Campos-Arceiz A: Concentrations of faecal glucocorticoid metabolites in Asian elephant's dung are stable for up to $8 \mathrm{~h}$ in a tropical environment. Conserv Physiol 4: cow070, 2016.
4. Wiedemair V, Mayr S, Wimmer DS, Köck EM, Penner S, Kerstan A, Steinmassl PA, Dumfahrt H and Huck CW: Novel molecular spectroscopic multimethod approach for monitoring water Absorption/Desorption kinetics of CAD/CAM Poly (Methyl methacrylate) prosthodontics. Appl Spectrosc 71: 1600-1612, 2017.

5. Yamakawa K, Ohira H, Matsunaga M and Isowa T: Prolonged effects of acute stress on decision-making under risk: A human psychophysiological study. Front Hum Neurosci 10: 444, 2016.

6. Kaynezhad P, Tachtsidis I and Jeffery G: Optical monitoring of retinal respiration in real time: $670 \mathrm{~nm}$ light increases the redox state of mitochondria. Exp Eye Res 152: 88-93, 2016.

7. Uludag A, Sahin EM, Agaoglu H, Gungor S, Ertekin YH and Tekin M: Are blood pressure values compatible with medication adherence in hypertensive patients? Niger J Clin Pract 19: 460-464, 2016.

8. Hillebrand M, Nouri G, Hametner B, Parragh S, Köster J, Mortensen K, Schwarz A, von Kodolitsch Y and Wassertheurer S: Ambulatory $(24 \mathrm{~h})$ blood pressure and arterial stiffness measurement in Marfan syndrome patients: A case control feasibility and pilot study. BMC Cardiovasc Disord 16: 81, 2016

9. Mishra S, Chauhan A and Jha S: Study of a structured action pathway and persistent monitoring tool among nurses to achieve cent percent management of hypoglycaemia in in-patients: A measure of quality of healthcare. Med J Armed Forces India 72: 27-32, 2016.

10. Mamykina L, Heitkemper EM, Smaldone AM, Kukafka R, Cole-Lewis H, Davidson PG, Mynatt ED, Tobin JN, Cassells A, Goodman C, et al: Structured scaffolding for reflection and problem solving in diabetes self-management: Qualitative study of mobile diabetes detective. J Am Med Inform Assoc 23: 129-136, 2016.

11. Yin ES, Downing NS, Li X, Singer SJ, Curry LA, Li J, Krumholz HM and Jiang L: Organizational culture in cardiovascular care in Chinese hospitals: A descriptive cross-sectional study. BMC Health Serv Res 15: 569, 2015.

12. Ishikawa J, Yoshino Y, Watanabe S and Harada K: Reduction in central blood pressure after bathing in hot water. Blood Press Monit 21: 80-86, 2016.

13. Olsson AL, Mitzel MR and Tufenkji N: QCM-D for non-destructive real-time assessment of Pseudomonas aeruginosa biofilm attachment to the substratum during biofilm growth. Colloids Surf B Biointerfaces 136: 928-934, 2015.

14. Jaykumar AB, Caceres PS, Sablaban I, Tannous BA and Ortiz PA: Real-time monitoring of NKCC2 endocytosis by total internal reflection fluorescence (TIRF) microscopy. Am J Physiol Renal Physiol 310: F183-F191, 2016.

15. Madrid E and Horswell SL: Effect of deuteration on phase behavior of supported phospholipid bilayers: A spectroelectrochemical study. Langmuir 31: 12544-12551, 2015.

16. Guo Q, He Y and Lu HP: Interrogating the activities of conformational deformed enzyme by single-molecule fluorescence-magnetic tweezers microscopy. Proc Natl Acad Sci USA 112: 13904-13909, 2015.

17. Lopes de Azambuja CR, dos Santos LG, Rodrigues MR, Rodrigues RF, da Silveira EF, Azambuja JH, Flores AF, Horn AP, Dora CL, Muccillo-Baisch AL, et al: Physico-chemical characterization of asolectin-genistein liposomal system: An approach to analyze its in vitro antioxidant potential and effect in glioma cells viability. Chem Phys Lipids 193: 24-35, 2015.

18. Ruijter BJ, van Putten MJ and Hofmeijer J: Generalized epileptiform discharges in postanoxic encephalopathy: Quantitative characterization in relation to outcome. Epilepsia 56: 1845-1854, 2015.

19. Chung CF, Cook J, Bales E, Zia J and Munson SA: More than telemonitoring: Health provider use and nonuse of Life-Log data in irritable bowel syndrome and weight management. J Med Internet Res 17: e203, 2015.

20. Yang Q, Wang H, Chen S, Lan X, Xiao H, Shi H and Ma Y: Fiber-optic-based micro-probe using hexagonal 1-in- 6 fiber configuration for intracellular Single-Cell $\mathrm{pH}$ measurement. Anal Chem 87: 7171-7179, 2015. 